\title{
Tumor suppressor miR-211-5p is associated with cellular migration, proliferation and apoptosis in renal cell carcinoma
}

\author{
JING QUAN ${ }^{1-3}$, XIANG PAN $^{1-3}$, TAO HE $^{1,3}$, CANBIN LIN $^{1,3}$, YULIN LAI ${ }^{1,3}$, PEIJIE CHEN $^{1,3}$, \\ ZENG ZHANG $^{2,3}$, SHANGQI YANG ${ }^{1}$, TAO WANG $^{4 *}$ and YONGQING LAI ${ }^{1,3^{*}}$
}

${ }^{1}$ Department of Urology, Peking University Shenzhen Hospital, Shenzhen, Guangdong 518036; ${ }^{2}$ Department of Urology, Anhui Medical University, Hefei, Anhui 230032; ${ }^{3}$ The Guangdong and Shenzhen Key Laboratory of Male Reproductive Medicine and Genetics, Peking University Shenzhen Hospital, Institute of Urology of Shenzhen PKU-HKUST Medical Center;

${ }^{4}$ Department of Cardiovascular Surgery, Peking University Shenzhen Hospital, Shenzhen, Guangdong 518036, P.R. China

Received April 29, 2017; Accepted November 3, 2017

DOI: $10.3892 /$ etm.2018.5908

\begin{abstract}
Increasing evidence has demonstrated that microRNA (miRNA) serve an important role in the tumorigenesis of various types of cancer, such as renal cell carcinoma (RCC). The expression of miR-211-5p has been detected in RCC tissue by microarray profiling. However, studies regarding miR-211-5p and RCC remain rare. In the present study, the expression of miR-211-5p in RCC tissues and cell lines was revealed to be downregulated by reverse transcription-quantitative polymerase chain reaction analyses. The present results also revealed that the upregulation or downregulation of miR-211-5p inhibited or promoted, respectively, RCC cell proliferation, migration and invasion. In addition, the upregulation or downregulation of miR-211-5p induced or inhibited, respectively, RCC cell apoptosis. However, the present study only identified that downregulation of miR-211-5p promoted 7860 and ACHN cell viability. The above results suggest that miR-211-5p may be a tumor suppressor in the tumorigenesis of RCC and may be a potential therapeutic target for RCC in the future. Further research should focus on the underlying mechanism of miR-211-5p in RCC and on investigating the possible use of miR-211-5p as a biomarker for RCC.
\end{abstract}

Correspondence to: Professor Yongqing Lai, Department of Urology, Peking University Shenzhen Hospital, 1120 Lianhua Road, Shenzhen, Guangdong 518036, P.R. China

E-mail: yqlord@163.com

Professor Tao Wang, Department of Cardiovascular Surgery, Peking University Shenzhen Hospital, 1120 Lianhua Road, Shenzhen, Guangdong 518036, P.R. China

E-mail: szwangtao@126.com

*Contributed equally

Key words: microRNA, miR-211-5p, renal cell carcinoma, tumor suppressor

\section{Introduction}

Renal cell carcinoma (RCC) is the most common type of malignant kidney cancer and occurs primarily on the renal tubular epithelial system, excluding metastatic neoplasms. In addition, due to the aberrant expression of genes in renal tubular epithelial cells, they gradually transform into RCC cells (1). In a study conducted in 2014, 3.9\% of new cancer cases were RCC, with a median age of 64 years at diagnosis in the USA alone (2). Due to the lack of typical clinical symptoms and an early diagnostic marker for RCC, metastasis has already developed in $\sim 40 \%$ of patients when RCC is diagnosed (3). Currently, surgery remains to be the most effective treatment strategy for RCC and an abundance of postoperative adjuvant therapies have been approved for treatment of RCC; however, the most effective treatment is unknown $(2,4)$. Therefore, it is necessary to identify a highly specific RCC-associated maker for early diagnosis of RCC.

MicroRNA (miRNA) are a family of short non-coding RNA, with a length of 19-25 nucleotides. miRNA guide the RNA-induced silencing complex to miRNA target sites (3' untranslated region of mRNA) and then regulate gene expression at the post-translational level, leading to the inhibition of translation or mRNA degradation (5). With increasing research, more and more studies have demonstrated that miRNA may serve an important role in the occurrence and development of various cancer types (6-8), such as RCC (9-11).

miR-211-5p was predicted using computational methods using conservation with mouse and Fugu rubripes sequences (12). The sequence maps to human chromosome 15 and miR-211-5p has been demonstrated to serve an important role in several cancer types, including colorectal cancer (CRC) (13), gastric cancer (14), non-small cell lung cancer (15) and hepatocellular carcinoma (16). The aim of the present study was to reveal the expression and function of miR-211-5p in RCC.

\section{Materials and methods}

Ethics statement. All patients signed the informed consent forms prior to initiation of the present study. The present 
study was approved by the Ethical Review Committee of the Peking University Shenzhen Hospital (Shenzhen, China) and complied with the Declaration of Helsinki.

Specimens and cell lines. RCC tissues and paired adjacent normal tissues were obtained from patients undergoing surgery at the Peking University Shenzhen Hospital from the 17th of March 2013 to the 30th of December 2015. The patients had not received any anticancer treatment prior to surgery. A total of 24 patients were enrolled in the present study (18 males and 6 females), with a mean age of 51 years. Once RCC tissues and paired adjacent normal tissues were completely removed, all tissues were immediately collected and stored at $-80^{\circ} \mathrm{C}$ until the RNA was later extracted. The clinical and pathological characteristics of the patients are presented in Table I.

RCC cell lines (ACHN, 786O, Caki-1 and 769P) and the human embryo kidney cell line (293T) were acquired from the Guangdong and Shenzhen Key Laboratory of Male Reproductive Medicine and Genetics (Shenzhen, China). All cells were cultured in Dulbecco's modified Eagle's medium (DMEM; Invitrogen; Thermo Fisher Scientific, Inc., Waltham, MA, USA) supplemented with $10 \%$ fetal bovine serum (FBS; Hyclone; GE Healthcare Life Sciences, Logan, UT, USA), $1 \%$ antibiotics $(100 \mathrm{U} / \mathrm{ml}$ penicillin and $100 \mathrm{mg} / \mathrm{ml}$ streptomycin; Gibco; Thermo Fisher Scientific, Inc.) and $1 \%$ glutamine. The cells were incubated in a $5 \% \mathrm{CO}_{2}$ humidified incubator at $37^{\circ} \mathrm{C}$.

$R N A$ extraction and reverse transcription-quantitative polymerase chain reaction ( $R T-q P C R)$. According to the manufacturer's protocol, total RNA from tissues and cells was isolated using TRIzol reagent (Invitrogen; Thermo Fisher Scientific, Inc.) and purified using an RNeasy Maxi kit (Qiagen $\mathrm{GmbH}$, Hilden, Germany). Following the measurement of the RNA concentration using a NanoDrop 2000c (Thermo Fisher Scientific, Inc.), an miScript II RT kit (Qiagen $\mathrm{GmbH}$ ) was used to synthetize cDNA with reverse transcriptase, according to manufacturer's protocol. The temperature protocol was as follows: $37^{\circ} \mathrm{C}$ for $60 \mathrm{~min}, 95^{\circ} \mathrm{C}$ for $5 \mathrm{~min}$ and kept at $4^{\circ} \mathrm{C}$. Subsequently, the expression of miR-211-5p was detected with an miScript SYBR ${ }^{\circledR}$ Green PCR kit (Qiagen $\mathrm{GmbH}$ ) by qPCR on a Roche light cycler 480 Real-Time PCR System (Roche Diagnostics, Basel, Switzerland). The $10 \mu 1$ reaction mixture consisted of $5 \mu 12 X$ QuantiTect SYBR Green PCR Master mix, $3.7 \mu 1$ RNase-free water, $1 \mu \mathrm{l}$ cDNA template, $0.4 \mu 1$ specific miRNA primer and 10X miScript Universal Primer. The forward primer of miR-211-5p was 5'-TTCCCTTTGUCATCC TTCGCCT-3' and the reverse primer was a universal primer, which was provided in the miScript SYBR ${ }^{\circledR}$ Green PCR kit. U6 was chosen as an internal control. The U6 primer sequences were as follows: Forward 5'-CTCGCTTCGGCAGCACA-3' and reverse 5'-ACGCTTCACGAATTTGCGT-3'. The thermocycling conditios were as follows: $95^{\circ} \mathrm{C}$ for $2 \mathrm{~min}, 95^{\circ} \mathrm{C}$ for $10 \mathrm{sec}, 55^{\circ} \mathrm{C}$ for $30 \mathrm{sec}$ and $72^{\circ} \mathrm{C}$ for $30 \mathrm{sec}$, for 40 cycles. The expression levels of miR-211-5p in tissues and cells were analyzed using the $2^{-\Delta \Delta \mathrm{Cq}}$ method (17).

Cell transfection. The expression of miR-211-5p in 7860 and ACHN cells was upregulated/downregulated by transfection of the synthesized miR-211-5p mimic/inhibitor (Shanghai GenePharma Co., Ltd., Shanghai, China) using
Lipofectamine $2000^{\circledR}$ (Invitrogen; Thermo Fisher Scientific, Inc.) and Opti-MEM ${ }^{\circledR}$ I Reduced Serum Medium (Gibco; Thermo Fisher Scientific, Inc.), following the manufacturer's protocol. The concentration of the miRNA mimic and inhibitors used for transfection are presented in Table II. The efficiency of transfection was measured by RT-qPCR as aforementioned. The sequences of the miRNA and primers used are presented in Table III.

MTT assay. The cell activity of the 7860 and ACHN cells was determined using an MTT assay. Cells ( $\sim 5,000$ cells/well) were seeded into 96-well plates and transfected with miR-211-5p mimic, inhibitor, negative control (NC) and inhibitor NC using Lipofectamine ${ }^{\circledR} 2000$. A total of $96 \mathrm{~h}$ later, $20 \mu \mathrm{l}$ MTT ( $5 \mathrm{mg} / \mathrm{ml}$; Sigma-Aldrich; Merck KGaA, Darmstadt, Germany) was added into each well of the 96-well plate. Following $4 \mathrm{~h}$ at $37^{\circ} \mathrm{C}, 100 \mu \mathrm{l}$ dimethyl sulfoxide (Sigma-Aldrich; Merck $\mathrm{KGaA}$ ) was added to each well. Subsequently, the 96-well plate was shocked in a reciprocating decolorization shaking table (TSB-108; Qilinbeier, Jiangsu, China) for $10 \mathrm{~min}$ in the dark at room temperature. Finally, the optical density (OD) value of each well was measured by an ELISA microplate reader (Bio-Rad Laboratories, Inc., Hercules, CA, USA) at a wavelength of $595 \mathrm{~nm}$ (with $620 \mathrm{~nm}$ as the reference wavelength).

Cell Counting Kit-8 (CCK-8) assay. The proliferation ability of the 7860 and ACHN cells was analyzed using a CCK-8 assay (Beyotime Institute of Biotechnology, Shanghai, China). Cells $(\sim 5,000$ cells/well) were seeded into a 96 -well plate and transfected according to the aforementioned protocol. Following transfection, $10 \mu$ 1 CCK-8 solution was added to each well and culture was continued for $30 \mathrm{~min}$ in the dark at room temperature. The OD value of each well was then measured using an ELISA microplate reader at a wavelength of $450 \mathrm{~nm}$ (with $620 \mathrm{~nm}$ as the reference wavelength) at 0,24 , 48 and $72 \mathrm{~h}$ following transfection.

Transwell assay. The migration and invasion ability of the $786 \mathrm{O}$ and ACHN cells in vitro was examined by Transwell assays. Transwell chambers (BD Biosciences, Franklin Lakes, NJ, USA) with Matrigel were used to assess invasion ability, while the Transwell chambers without Matrigel were used to assess migration ability. A total of $24 \mathrm{~h}$ after transfection, $\sim 2 \times 10^{4}$ cells were added into each upper chamber with DMEM and DMEM supplemented with $10 \%$ FBS was added to the lower chambers. The chambers were incubated for $48 \mathrm{~h}$ in a $5 \% \mathrm{CO}_{2}$ incubator at $37^{\circ} \mathrm{C}$. The cells in the lower chamber were fixed and stained successively by $4 \%$ paraformaldehyde and crystal violet each for $20 \mathrm{~min}$ at room temperature. Finally, a light microscope was used to observe the cells in the bottom of chamber at a magnification of $\mathrm{x} 100$.

Wound scratch assay. The migration ability of the 7860 and ACHN cells in vitro was also examined by wound scratch assays. In total, $\sim 1 \times 10^{6}$ cells were cultured in each well of a 6-well plate. After $24 \mathrm{~h}$, cells were transfected with miR-211-5p mimic, inhibitor, NC and inhibitor NC using Lipofectamine ${ }^{\circledR} 2000$. A vertical line was scratched in the cells using a sterile $1-\mathrm{ml}$ pipette tip. The images of the scratches were respectively captured by a digital camera system at 0,12 and $24 \mathrm{~h}$. 
Table I. Clinicopathological characteristics of patients with renal cell carcinoma.

\begin{tabular}{lc}
\hline Characteristic & Number of cases \\
\hline Mean age, range (years) & $51(27-72)$ \\
Sex & 18 \\
Male & 6 \\
Female & \\
Histological type & 20 \\
Clear cell & 4 \\
Papillary & \\
Fuhrman grade & 15 \\
I & 7 \\
II & 1 \\
III & 1 \\
IV & \\
American Joint Committee on & \\
Cancer clinical stage & 15 \\
I & 8 \\
II & 1 \\
III+IV & \\
\hline
\end{tabular}

Table II. Concentration of the miRNA mimic/inhibitors used for the transfection.

\begin{tabular}{lccc}
\hline Plate & siRNA & Final volume & Lipo2000 \\
\hline 96-well & $0.5 \mu 1(5 \mathrm{pmol})$ & $100 \mu 1$ & $0.25 \mu 1$ \\
24-well & $1 \mu 1(20 \mathrm{pmol})$ & $500 \mu 1$ & $1 \mu 1$ \\
12-well & $2 \mu 1(40 \mathrm{pmol})$ & $1 \mathrm{ml}$ & $2 \mu 1$ \\
6-well & $5 \mu 1(100 \mathrm{pmol})$ & $2 \mathrm{ml}$ & $5 \mu 1$ \\
\hline
\end{tabular}

siRNA, small interfering RNA.

Flow cytometry assay. The apoptosis rate of the $786 \mathrm{O}$ and $\mathrm{ACHN}$ cells in vitro was analyzed by a flow cytometry assay. In total, $\sim 1 \times 10^{6}$ cells were incubated in each well of the 6 -well plate and were transfected following the manufacturer's instructions. All cells were harvested after $48 \mathrm{~h}$ and washed twice with cold PBS. Following this, $100 \mu 1 \mathrm{X}$ binding buffer (Invirtogen; Thermo Fisher Scientific, Inc.) was used to resuspend the cells. Next, $5 \mu \mathrm{l}$ Annexin V-fluorescein isothiocyanate (Invitrogen; Thermo Fisher Scientific, Inc.) and $5 \mu \mathrm{l}$ propidium iodide (Invitrogen; Thermo Fisher Scientific, Inc.) were added to the experimental group and stained for $15 \mathrm{~min}$ in the dark at room temperature. Finally, the apoptosis rate was analyzed by flow cytometry (EPICS Xl-4; Beckman Coulter, Inc., Brea, CA, USA) after adding $400 \mu \mathrm{l} 1 \mathrm{X}$ binding buffer to each tube. All assays were repeated at least three times. FlowJo 7.6.1 software was utilized for the analysis of results (FlowJo LLC, Ashland, OR, USA).

Statistical analyses. Data were presented as the mean \pm standard error of the mean. Significance of differential expression was analyzed by using the Student's t-test, while paired t-tests were used to compare the expression levels of miR-211-5p in matched tumor/normal tissues. One-way analysis of variance followed by Bonferroni's post hoc tests were used to compare the expression level of miR-211-5p in RCC cell lines. SPSS 23.0 (IBM Corp., Armonk, NY, USA) was used for all statistical analyses. $\mathrm{P}<0.05$ was considered to indicate a statistically significant difference.

\section{Results}

Expression level of miR-211-5p is downregulated in RCC tissues and cell lines. The relative expression level of miR-211-5p in RCC tissues is demonstrated in the Fig. 1A. As indicated in Fig. 1B, the expression level of miR-211-5p in RCC tissues $(1.000 \pm 0.466)$ was significantly lower than that in adjacent normal tissues $(3.664 \pm 0.407)(\mathrm{P}<0.05)$. The results of miR-211-5p expression in the cell lines demonstrated that the relative expression of miR-211-5p was significantly lower in $7860(0.252 \pm 0.032, \mathrm{P}<0.01)$ and ACHN cells $(0.253 \pm 0.032$, $\mathrm{P}<0.001)$ than in $293 \mathrm{~T}$ cells $(1.000 \pm 0.217)$. However, there was no significant difference between the expression level in Caki-1 (0.772 $\pm 0.355, \mathrm{P}=0.401)$ and 769P cells $(1.341 \pm 0.441$, $\mathrm{P}=0.366$ ) compared with that in $293 \mathrm{~T}$ cells (Fig. 1C). The above results suggest that miR-211-5p may act as a tumor suppressor in RCC.

Cell transfection efficiency validation. RT-qPCR was performed to detect the transfection efficiency of miR-211-5p mimic or inhibitor, compared with NC or inhibitor NC. The results demonstrated that the expression levels of miR-211-5p were $0.234 \pm 0.032$ times higher $(7860$ cells, $\mathrm{P}=0.003)$ and $0.293 \pm 0.048$ times higher $(\mathrm{ACHN}$ cells, $\mathrm{P}=0.005)$ in cells transfected with miR-211-5p inhibitor compared with the levels in those transfected with inhibitor NC after $24 \mathrm{~h}$. The

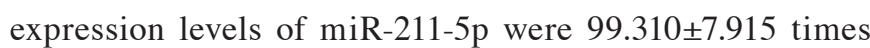
higher $(7860$ cells, $\mathrm{P}=0.021)$ and $91.321 \pm 36.326$ times higher (ACHN cells, $\mathrm{P}=0.018$ ) in cells transfected with miR-211-5p mimic compared with the levels in those transfected with NC after $24 \mathrm{~h}$ (Fig. 1D).

Downregulation of miR-211-5p promotes 7860 and ACHN cell viability. Cell viability was analyzed using an MTT assay. The results revealed that the relative viability of 7860 cells transfected with miR-211-5p inhibitor was significantly increased compared with that observed in cells transfected with inhibitor NC $(1.117 \pm 0.100$ vs. $1.000 \pm 0.090$, respectively; $\mathrm{P}<0.001$; Fig. 2A). The relative viability of ACHN cells was also significantly increased in cells transfected with miR-211-5p inhibitor compared with that observed in cells transfected with inhibitor NC $(1.075 \pm 0.077$ vs. $1.000 \pm 0.082$, respectively; $\mathrm{P}<0.05$; Fig. $2 \mathrm{~B}$ ). However, there was no significant difference observed between the mimic group and $\mathrm{NC}$ group for the viability of 7860 and $\mathrm{ACHN}$ cells $(\mathrm{P}>0.05$; data not shown).

Upregulation/downregulation of miR-211-5p inhibits/promotes 7860 and ACHNcell proliferation. ACCK-8 assay was performed to assess the proliferation ability of 7860 and ACHN cells (Fig. 3). The results demonstrated that the upregulation/downregulation 
Table III. Sequences of primers and miRNA.

\begin{tabular}{lcl}
\hline Primer/miRNA & Direction & \multicolumn{1}{c}{ Sequence $\left(5^{\prime}-3^{\prime}\right)$} \\
\hline miR-211-5p & $\mathrm{F}$ & TTCCCTTTGUCATCCTTCGCCT \\
U6 & $\mathrm{R}$ & Universal primers (miScript SYBR Green polymerase chain reaction kit) \\
& $\mathrm{F}$ & CTCGCTTCGGCAGCACA \\
miR-211-5p mimic & $\mathrm{R}$ & ACGCTTCACGAATTTGCGT \\
& $\mathrm{F}$ & UUCCCUUUGUCAUCCUUCGCCU \\
miR-211-5p inhibitor & $\mathrm{R}$ & GCGAAGGAUGACAAAGGGAAUU \\
NC & - & AGGCGAAGGAUGACAAAGGGAA \\
& $\mathrm{F}$ & UUCUCCGAACGUGUCACGUTT \\
Inhibitor NC & $\mathrm{R}$ & ACGUGACACGUUCGGAGAATT \\
\hline
\end{tabular}

miRNA, microRNA; NC, negative control; F, forward; R, reverse.
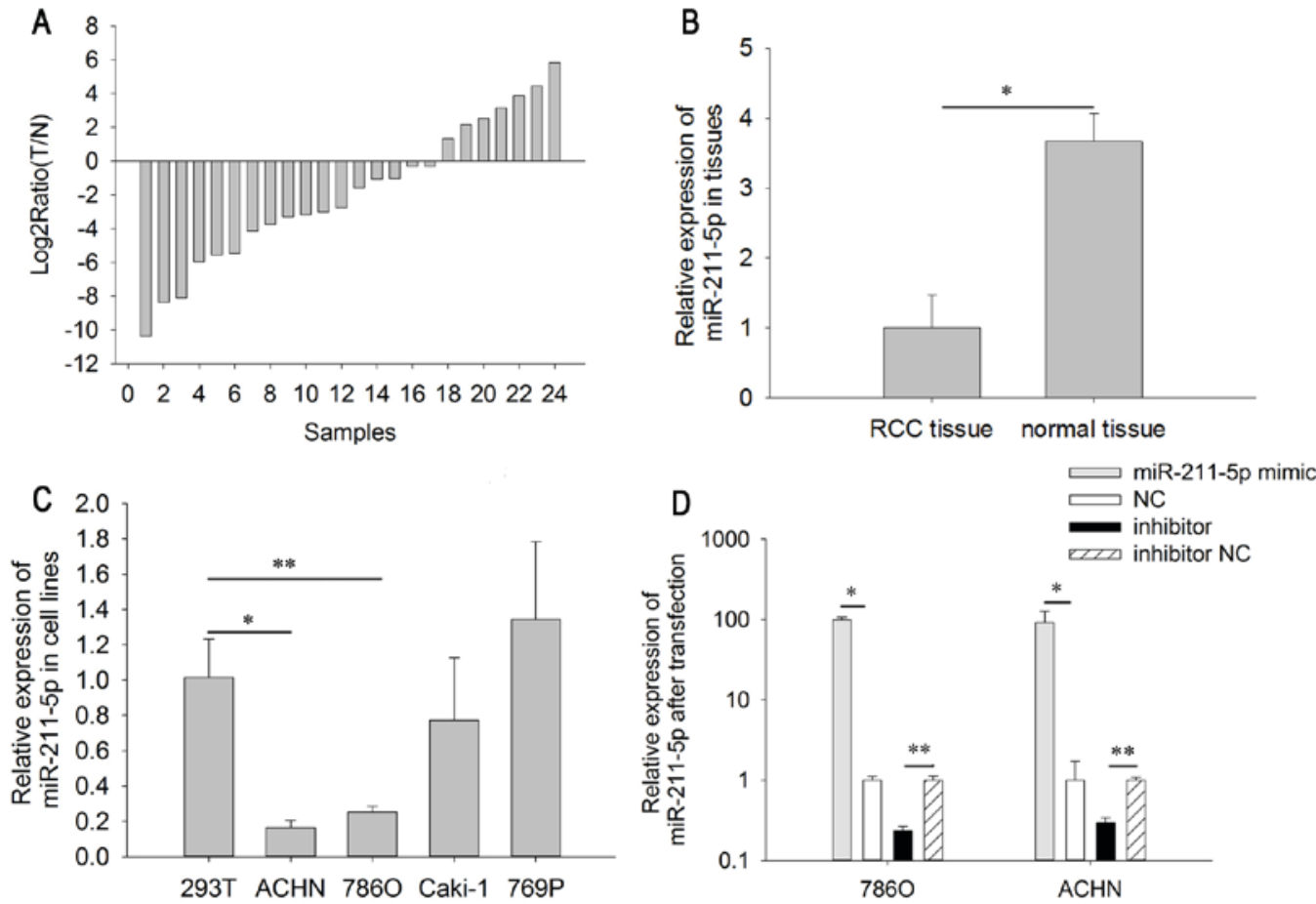

Figure 1. Relative expression of miR-211-5p in 24 paired tissues and cell lines. (A) Log2 ratios of miR-211-5p expression in 24 paired Ts and adjacent Ns. (B) The relative expression of miR-211-5p in T and N. (C) The relative expression of miR-211-5p in RCC cell lines. (D) The relative expression of miR-211-5p following transfection in 7860 and ACHN cells. ${ }^{*} \mathrm{P}<0.05$ and ${ }^{* *} \mathrm{P}<0.01$ as indicated. $\mathrm{T}, \mathrm{RCC}$ tissues; $\mathrm{N}$, normal tissue; RCC, renal cell carcinoma; $\mathrm{NC}$, negative control.

of miR-211-5p inhibited/promoted the proliferation of the 7860 and ACHN cells. Proliferation was downregulated by 14.030 $(\mathrm{P}<0.05), 16.802(\mathrm{P}<0.05)$ and $19.416 \%(\mathrm{P}<0.05)($ Fig. $3 \mathrm{~A})$ in $786 \mathrm{O}$ cells, and $16.385(\mathrm{P}=0.150), 12.627(\mathrm{P}<0.05)$ and $17.886 \%$ $(\mathrm{P}<0.01)$ (Fig. 3C) in ACHN cells following transfection with miR-211-5p mimic at 24, 48 and $72 \mathrm{~h}$, respectively, compared with that observed in cells transfected with NC. Proliferation was upregulated by $29.957(\mathrm{P}<0.05), 16.118(\mathrm{P}<0.05)$ and $31.945 \%(\mathrm{P}<0.01)($ Fig. 3B) in 7860 cells, and $11.691(\mathrm{P}=0.095)$, $26.840(\mathrm{P}<0.05)$ and $27.187 \%(\mathrm{P}<0.01)($ Fig. 3D) in ACHN cells following transfection with miR-211-5p inhibitor at 24, 48 and
$72 \mathrm{~h}$, respectively, compared with that observed in cells transfected with inhibitor NC.

Upregulation/downregulation of miR-211-5p inhibits/ promotes 7860 and ACHN cell mobility. To analyze the mobility of $786 \mathrm{O}$ and ACHN cells, wound scratch and Transwell assays were designed (Figs. 4 and 5). The results of Transwell assays demonstrated that the migratory ability of 7860 cells was significantly downregulated by $35.351 \%$ $(\mathrm{P}<0.01)$ in the miR-211-5p mimic group compared with that observed in the NC group (Fig. 4). Furthermore, the 

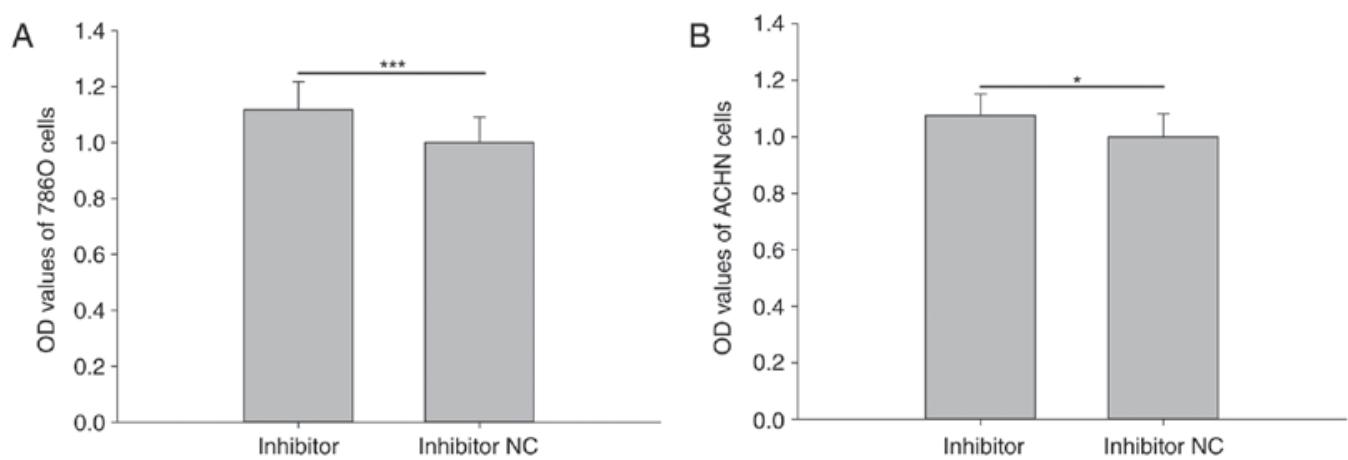

Figure 2. Cell viability assay following transfection with miR-211-5p inhibitor or inhibitor NC. Results of cell viability assay in (A) $786 \mathrm{O}$ and (B) ACHN cells following transfection with miR-211-5p inhibitor or inhibitor NC. ${ }^{*} \mathrm{P}<0.05$ and ${ }^{* * *} \mathrm{P}<0.001$ as indicated. NC, negative control; OD, optical density.
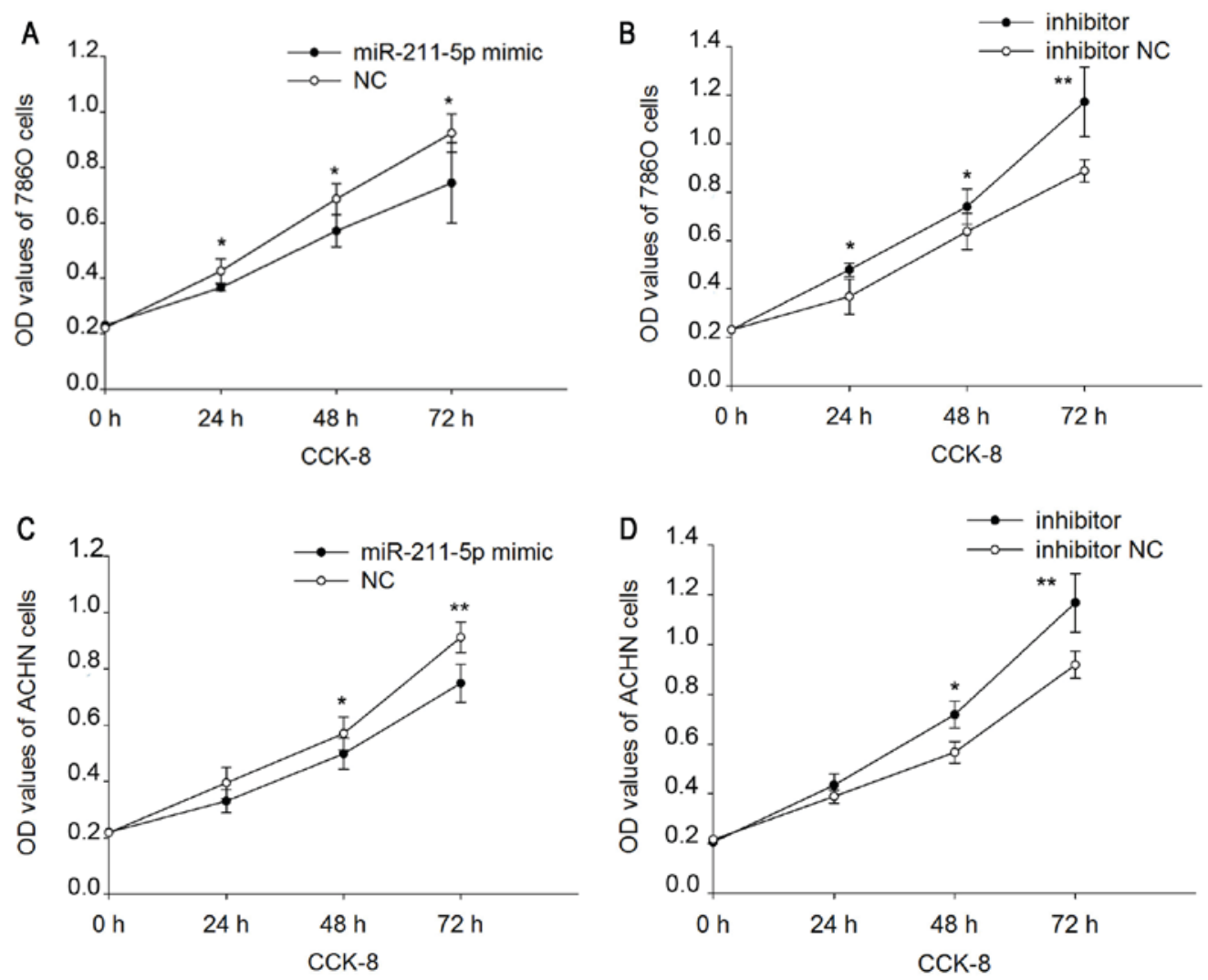

Figure 3. Cell proliferation assay of $786 \mathrm{O}$ and ACHN cells. A CCK-8 assay was used to measure cell proliferation in $786 \mathrm{O}$ cells transfected with (A) miR-211-5p mimic or NC and (B) miR-211-5p inhibitor or inhibitor NC. Cell proliferation was also measured in ACHN cells transfected with (C) miR-211-5p mimic or NC and (D) miR-211-5p inhibitor or inhibitor NC. ${ }^{*} \mathrm{P}<0.05$ and ${ }^{* *} \mathrm{P}<0.01$ vs. miR-211-5p mimic or inhibitor NC. CCK-8, Cell Counting Kit-8; NC, negative control; OD, optical density.

migratory ability of $786 \mathrm{O}$ cells was significantly upregulated by $34.207 \%(\mathrm{P}<0.05)$ in the miR-211-5p inhibitor group compared with the level observed in the inhibitor $\mathrm{NC}$ group. In ACHN cells, the migratory ability was significantly downregulated by $24.582 \%(\mathrm{P}<0.01)$ in the $\mathrm{miR}-211-5 \mathrm{p}$ mimic group compared with that observed in the $\mathrm{NC}$ group. The migratory ability was significantly upregulated by $38.620 \%$ $(\mathrm{P}<0.05)$ in $\mathrm{ACHN}$ cells of the miR-211-5p inhibitor group compared with the level observed in the inhibitor NC group (Fig. 5).

In order to determine the invasive ability of cells, Transwell chambers with Matrigel were utilized. The invasive ability of 7860 cells was significantly downregulated by $35.351 \%$ $(\mathrm{P}<0.05)$ in the miR-211-5p mimic group compared with that observed in the NC group. The invasive ability of 7860 cells was significantly upregulated by $34.207 \%(\mathrm{P}<0.05)$ in the miR-211-5p inhibitor group compared with that observed in the inhibitor NC group (Fig. 4). In addition, the invasive ability of ACHN cells was significantly downregulated by $31.625 \%$ $(\mathrm{P}<0.05)$ in the miR-211-5p mimic group compared with that observed in the $\mathrm{NC}$ group, while the invasive ability of ACHN cells was significantly upregulated by $37.628 \%(\mathrm{P}<0.05)$ in the miR-211-5p inhibitor group compared with that observed in the inhibitor NC group (Fig. 5). 

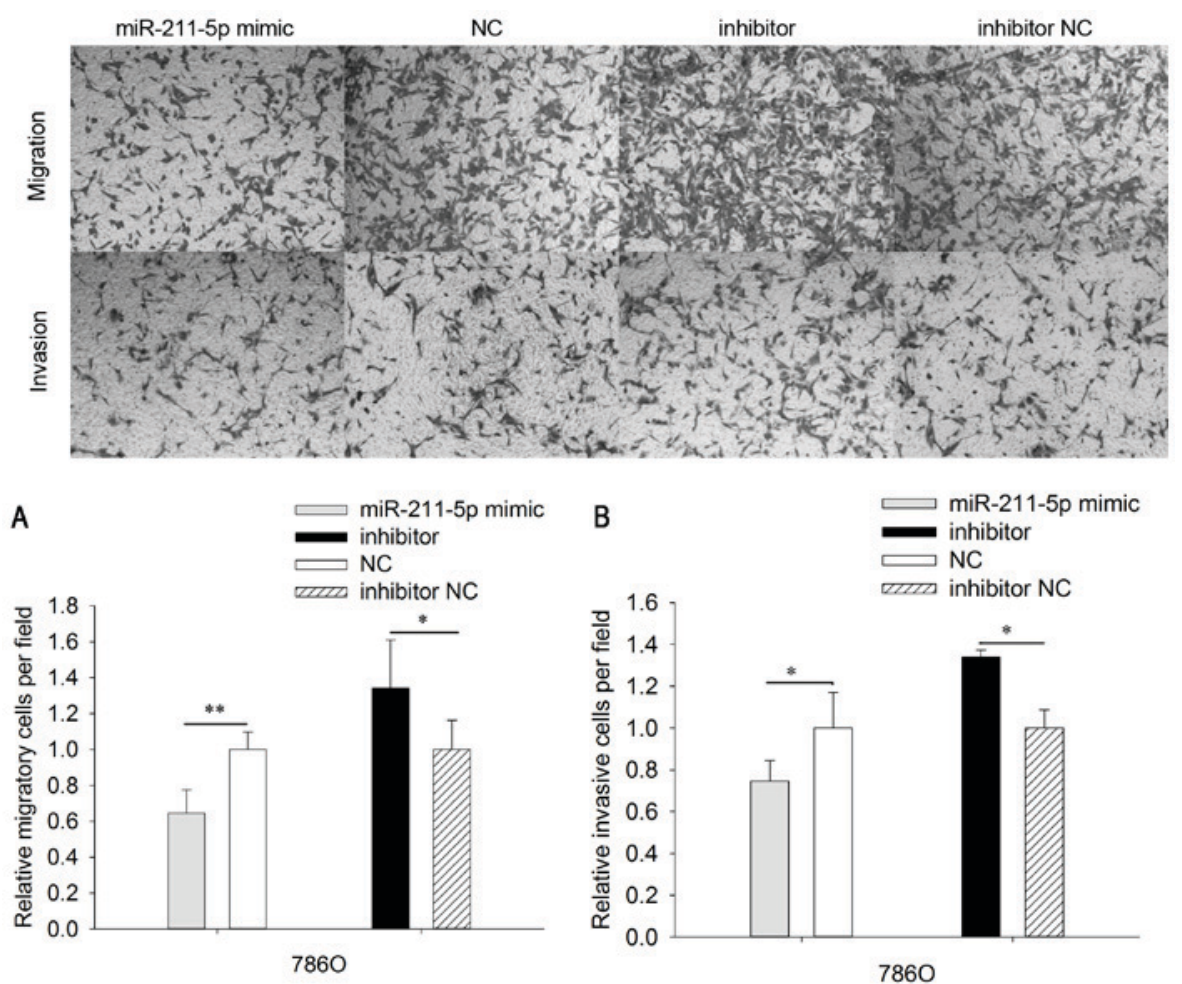

Figure 4. Migration and invasion assays of $786 \mathrm{O}$ cells. The cell (A) migratory and (B) invasion abilities of $786 \mathrm{O}$ cells transfected with miR-211-5p mimic or NC and miR-211-5p inhibitor or inhibitor NC were measured using Transwell assays (magnification, $\mathrm{x} 100$ ). ${ }^{*} \mathrm{P}<0.05$ and ${ }^{* *} \mathrm{P}<0.01$ as indicated. NC, negative control.
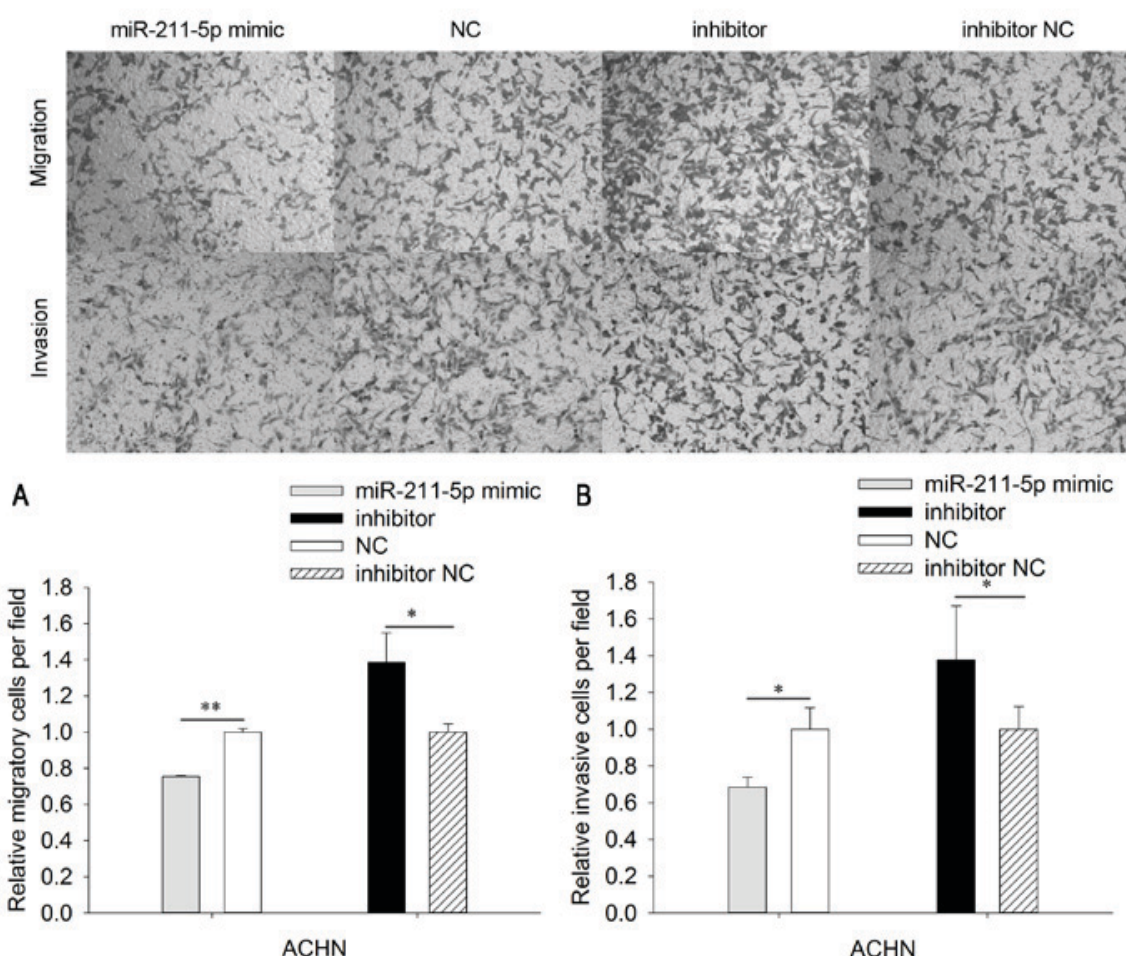

Figure 5. Migration and invasion assays of ACHN cells. The cell (A) migratory and (B) invasion abilities of ACHN cells transfected with miR-211-5p mimic or NC and miR-211-5p inhibitor or inhibitor NC were measured using Transwell assays (magnification, $100 \mathrm{x}$ ). ${ }^{*} \mathrm{P}<0.05$ and ${ }^{* *} \mathrm{P}<0.01$ as indicated. NC, negative control.

The results of the scratch wound assay demonstrated that the migratory ability of 7860 cells was significantly downregulated by $23.131 \%(\mathrm{P}<0.01)$ in the miR-211-5p mimic group compared with that observed in the NC group, while the migratory ability was significantly upregulated by $21.287 \%$ $(\mathrm{P}<0.001)$ in the miR-211-5p inhibitor group compared with the observed in the inhibitor NC group. The results in ACHN cells were similar to those in the 7860 cells, which demonstrated 


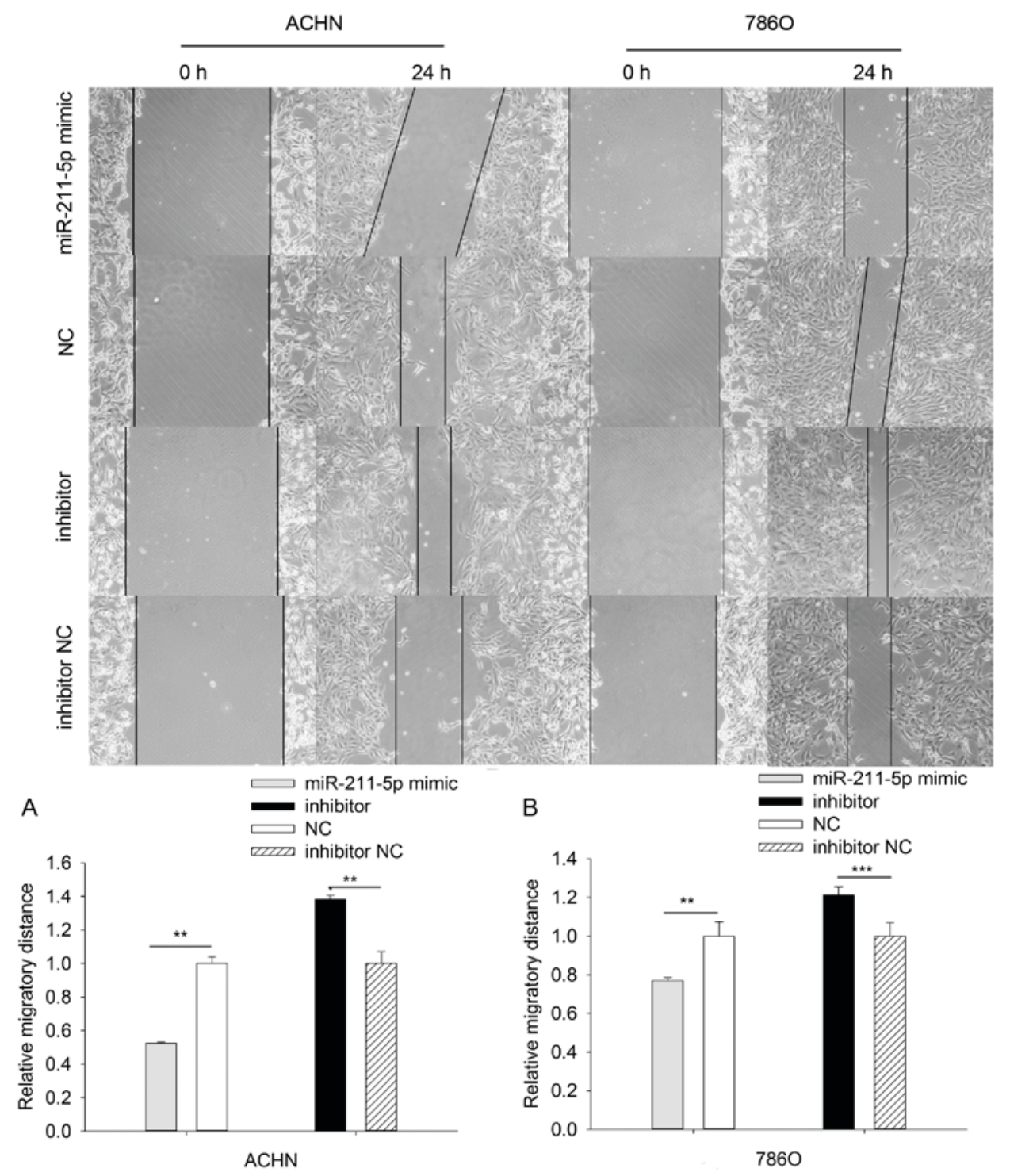

Figure 6. Wound scratch assays to determine the migratory ability of (A) ACHN and (B) $786 \mathrm{O}$ cells transfected with miR-211-5p mimic or NC and miR-211-5p inhibitor or inhibitor $\mathrm{NC} .{ }^{* *} \mathrm{P}<0.01$ and ${ }^{* * * *} \mathrm{P}<0.001$ as indicated. $\mathrm{NC}$, negative control.

that the migratory ability was significantly downregulated by $47.671 \%(\mathrm{P}<0.01)$ in the miR-211-5p mimic group compared with that observed in the NC group, while the migratory ability was significantly upregulated by $38.300 \%(\mathrm{P}<0.01)$ in the miR-211-5p inhibitor group compared with the observed in the inhibitor NC group (Fig. 6).

Upregulation/downregulation of miR-211-5p induces/inhibits 7860 and ACHN cell apoptosis. Flow cytometry was performed to analyze the apoptotic rate of cells (Figs. 7 and 8). The results demonstrated that the apoptotic rate of 7860 cells transfected with miR-211-5p mimic was significantly increased compared with that observed in the NC group $(25.333 \pm 4.854$ vs. 20.100 $\pm 3.000 \%$, respectively; $\mathrm{P}<0.05$; Fig. 7). A similar outcome was also observed in ACHN cells, with an apoptotic rate of $42.567 \pm 13.723$ vs. $30.633 \pm 12.548 \%(\mathrm{P}<0.01)$ in the miR-211-5p mimic and NC groups, respectively (Fig. 8). Additionally, the apoptotic rate of 7860 cells transfected with miR-211-5p inhibitor was significantly decreased compared with that observed in the inhibitor NC group $(7.453 \pm 1.243$ vs. $20.933 \pm 2.155 \%$, respectively; $\mathrm{P}<0.01$; Fig. 7). Similarly, the apoptotic rate of ACHN cells was 5.963 \pm 2.170 and $21.767 \pm 3.350 \%(\mathrm{P}<0.05)$ in the inhibitor and inhibitor $\mathrm{NC}$ groups, respectively (Fig. 8). These results suggest that the upregulation/downregulation of miR-211-5p induced/inhibited $786 \mathrm{O}$ and ACHN cell apoptosis.

\section{Discussion}

It is well known that miRNA are important post-transcriptional regulators and that they are involved in various physiological and pathological processes, including cell differentiation, cell proliferation and tumorigenesis (18). miRNA have been demonstrated to serve as oncogenes when they are overexpressed or tumor suppressor genes when they downregulated (19). Previous studies have indicated that miR-211-5p was downregulated in hepatocellular carcinoma, gastric cancer and ovarian cancer $(14,16,20)$. However, miR-211-5p was overexpressed in non-small cell lung cancer (15). Previous microarray analyses indicated that miR-211-5p was significantly downregulated in 

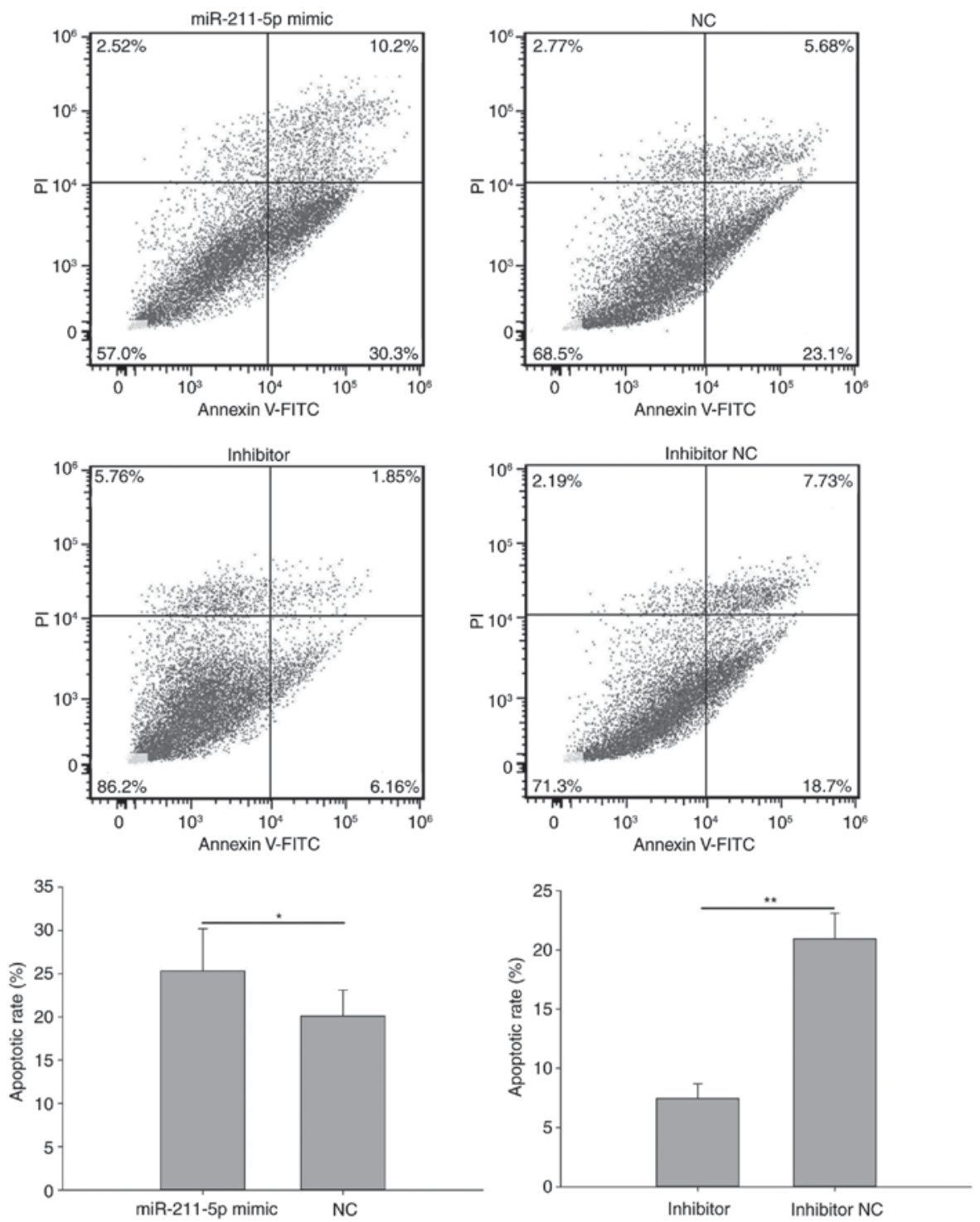

Figure 7. Flow cytometry results of the apoptosis rates in $786 \mathrm{O}$ cells transfected with miR-211-5p mimic or NC and miR-211-5p inhibitor or inhibitor NC. ${ }^{*} \mathrm{P}<0.05$ and ${ }^{* * *} \mathrm{P}<0.01$ as indicated. NC, negative control; PI, propidium iodide; FITC, fluorescein isothiocyanate.

RCC tissue compared with adjacent normal tissues (21). The results of the present study also indicated that the expression of miR-211-5p was downregulated in human RCC tissues and cell lines, according to RT-qPCR.

Furthermore, the present study also demonstrated that miR-211-5p has a negative impact in RCC cell lines, particularly on migration and invasion. This result was similar to that demonstrated in a study by Wang et al (22). In addition, the present study indicated that upregulation/downregulation of miR-211-5p induced/inhibited $786 \mathrm{O}$ and ACHN cell apoptosis. This phenomenon was also demonstrated in ovarian cancer (20). It has also been suggested that miR-211 acted as a tumor suppressor in epithelial ovarian cancer (EOC) and inhibited cell proliferation by regulating cyclin-dependent kinase 6 in EOC cells (20). In addition, long non-coding (lnc)RNA ucoo2kmd.1 was highly expressed in CRC tissues compared with adjacent normal tissues and regulated cluster of differentiation 44 as a molecular decoy for miR-211-3p (13). However, a study by $\mathrm{Xu}$ et al (23) revealed that miR-211-3p served as an oncogene in CRC and promoted cell proliferation by targeting lncRNA tumor suppressor candidate 7 in CRC cell lines. Furthermore, a case-control study discovered that miR-211 was associated with poor prognosis in CRC, while no statistically significant differences between clinicopathological factors and miR-211 expression level were identified in the CRC group (24).

In addition to cancer, miR-211 also serves an important role in the initiation and development of other diseases. A study by Sun et al (25) indicated that miR-133, miR-135, miR-204 and miR-211 acted as negative regulators and inhibited differentiation of osteoprogenitors by attenuating the essential transcription factor Runt-related transcription factor 2 (RUNX2). Furthermore, Atlasi et al (26) demonstrated that miR-211 acted as an endogenous attenuator of this transcription factor and the effect in calcium deposition did not correlate with the effect in RUNX2, which demonstrated that miR-211 could exert its effects on calcification through the Wnt signaling pathway. In addition, a study by Panizo et al (27) concluded that miR-29b, miR-133b and miR-211 have direct roles in vascular smooth muscle calcification induced by high phosphorus, and may be novel therapeutic targets in the management of vascular calcification. 

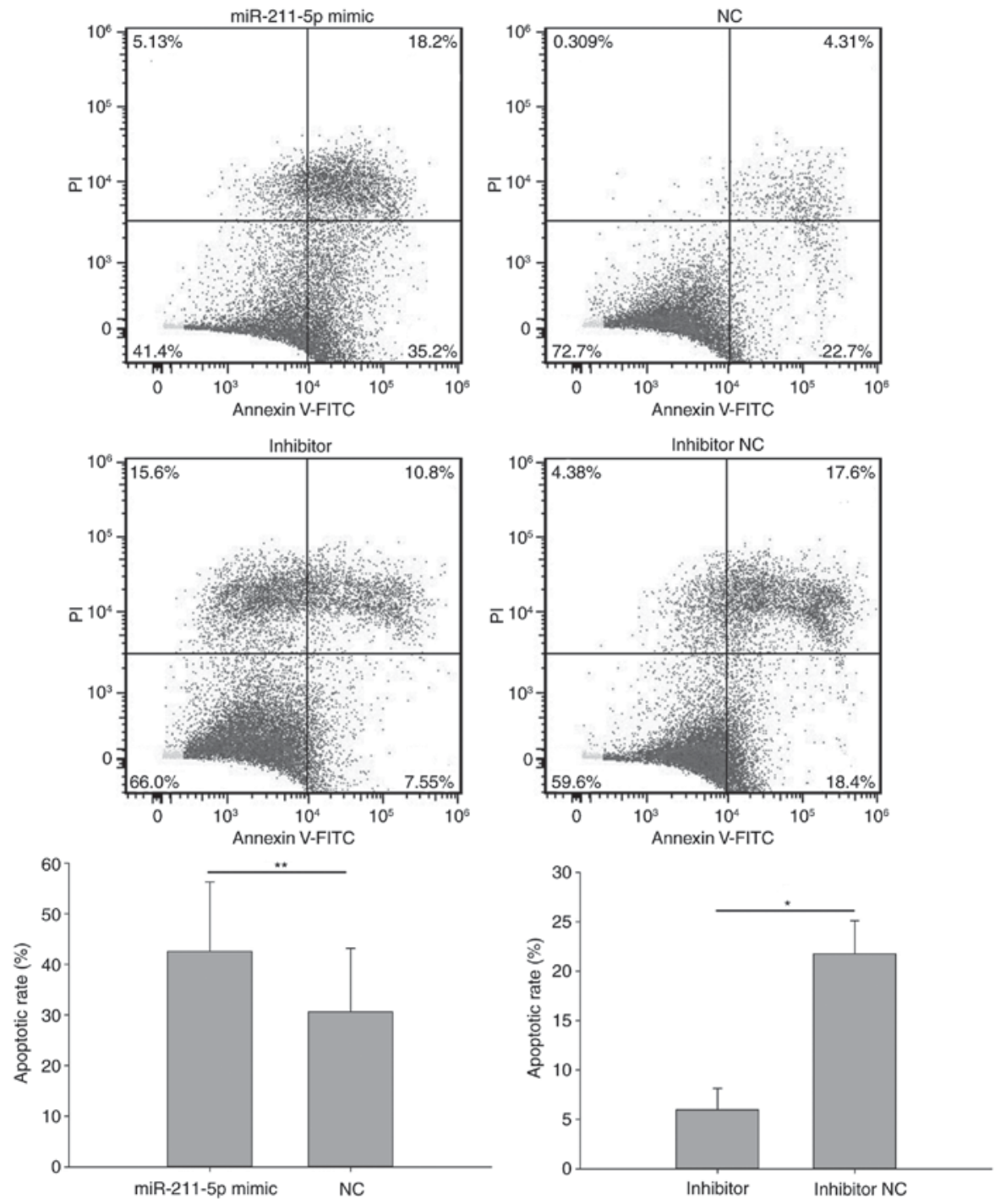

Figure 8. Flow cytometry results of the apoptosis rates in ACHN cells transfected with miR-211-5p mimic or NC and miR-211-5p inhibitor or inhibitor NC. ${ }^{*} \mathrm{P}<0.05$ and ${ }^{* *} \mathrm{P}<0.01$ as indicated. NC, negative control; PI, propidium iodide; FITC, fluorescein isothiocyanate.

In conclusion, the present study demonstrated that miR-211-5p was downregulated in RCC tissues and cell lines. The present study also indicated that miR-211-5p serves important roles in cellular functions, including proliferation, migration, invasion and apoptosis. Thus, this study suggests that miR-211-5p acts as a tumor suppressor in RCC. Further research should focus on the underlying mechanism of miR-211-5p in RCC and on investigating the possible use of miR-211-5p as a biomarker for RCC.

\section{Acknowledgements}

The authors thank reviewers for helpful comments on the manuscript and all the patients for consenting to provide tissue samples.

\section{Funding}

This study was supported by grants from the National Natural Science Foundation of China (grant no. 81101922), Science and Technology Development Fund Project of Shenzhen (grant nos. JCYJ20150403091443329 and JCYJ20170307111334308), the fund of 'San-ming' Project of Medicine in Shenzhen (grant no. SZSM201612066) and the fund of Guangdong Key Medical Subject.

\section{Availability of data and materials}

The analyzed data sets generated during the present study are available from the corresponding author on reasonable request.

\section{Authors' contributions}

YL and TW conceived and designed the experiments. JQ, XP, TH, CL and PC performed the experiments, analyzed the data and drafted the paper. ZZ and SY conceived the experiments. All authors have read and approved this manuscript.

\section{Ethics approval and consent to participate}

All patients signed the informed consent forms prior to initiation of the present study. The present study was approved by 
the Ethical Review Committee of the Peking University Shenzhen Hospital (Shenzhen, China) and complied with the Declaration of Helsinki.

\section{Consent for publication}

Not applicable.

\section{Competing interests}

The authors declare that they have no competing interests.

\section{References}

1. Chow WH, Dong LM and Devesa SS: Epidemiology and risk factors for kidney cancer. Nat Rev Urol 7: 245-257, 2010.

2. Motzer RJ, Jonasch E, Agarwal N, Beard C, Bhayani S, Bolger GB, Chang SS, Choueiri TK, Costello BA, Derweesh IH, et al: Kidney cancer, version 3.2015. J Natl Compr Canc Netw 13: 151-159, 2015.

3. Flanigan RC, Campbell SC, Clark JI and Picken MM: Metastatic renal cell carcinoma. Curr Treat Options Oncol 4: 385-390, 2003.

4. Afriansyah A, Hamid AR, Mochtar CA and Umbas R: Targeted therapy for metastatic renal cell carcinoma. Acta Med Indones 48: 335-347, 2016

5. Bartel DP: MicroRNAs: Genomics, biogenesis, mechanism and function. Cell 116: 281-297, 2004.

6. Shui Y, Yu X, Duan R, Bao Q, Wu J, Yuan H and Ma C: miR-130b-3p inhibits cell invasion and migration by targeting the Notch ligand Delta-like 1 in breast carcinoma. Gene 609: 80-87, 2017.

7. Chang C, Liu T, Huang Y, Qin W, Yang H and Chen J: MicroRNA-134-3p is a novel potential inhibitor of human ovarian cancer stem cells by targeting RAB27A. Gene 605: 99-107, 2017.

8. Chen T, Ren H, Thakur A, Yang T, Li Y, Zhang S, Wang T and Chen M: miR-382 inhibits tumor progression by targeting SETD8 in non-small cell lung cancer. Biomed Pharmacother 86 248-253, 2017.

9. Zhou W, Bi X, Gao G and Sun L: miRNA-133b and miRNA-135a induce apoptosis via the JAK2/STAT3 signaling pathway in human renal carcinoma cells. Biomed Pharmacother 84: 722-729, 2016.

10. Jin L, Li Y, Liu J, Yang S, Gui Y, Mao X, Nie G and Lai Y: Tumor suppressor miR-149-5p is associated with cellular migration, proliferation and apoptosis in renal cell carcinoma. Mol Med Rep 13: 5386-5392, 2016.

11. Kurozumi A, Kato M, Goto Y, Matsushita R, Nishikawa R, Okato A, Fukumoto I, Ichikawa T and Seki N: Regulation of the collagen cross-linking enzymes LOXL2 and PLOD2 by tumor-suppressive microRNA-26a/b in renal cell carcinoma. Int J Oncol 48: 1837-1846, 2016.

12. Lim LP, Glasner ME, Yekta S, Burge CB and Bartel DP: Vertebrate microRNA genes. Science 299: 1540, 2003.
13. Wu X, He X, Li S, Xu X, Chen X and Zhu H: Long Non-Coding RNA ucoo $2 \mathrm{kmd} .1$ regulates CD44-dependent cell growth by competing for miR-211-3p in colorectal cancer. PLoS One 11: e0151287, 2016.

14. Wang CY, Hua L, Sun J, Yao KH, Chen JT, Zhang JJ and Hu JH: MiR-211 inhibits cell proliferation and invasion of gastric cancer by down-regulating SOX4. Int J Clin Exp Pathol 8: 14013-14020, 2015.

15. Ye L, Wang H and Liu B: miR-211 promotes non-small cell lung cancer proliferation by targeting SRCIN1. Tumour Biol 37: 1151-1157, 2016.

16. Jiang G, Cui Y, Yu X, Wu Z, Ding G and Cao L: miR-211 suppresses hepatocellular carcinoma by downregulating SATB2. Oncotarget 6: 9457-9466, 2015.

17. Livak KJ and Schmittgen TD: Analysis of relative gene expression data using real-time quantitative PCR and the 2(-Delta Delta C(T)) method. Methods 25: 402-408, 2001.

18. Lee RC, Feinbaum RL and Ambros V: The C. elegans heterochronic gene lin-4 encodes small RNAs with antisense complementarity to lin-14. Cell 75: 843-854, 1993.

19. Shenouda SK and Alahari SK: MicroRNA function in cancer: Oncogene or a tumor suppressor? Cancer Metastasis Rev 28: 369-378, 2009.

20. Xia B, Yang S, Liu T and Lou G: miR-211 suppresses epithelial ovarian cancer proliferation and cell-cycle progression by targeting Cyclin D1 and CDK6. Mol Cancer 14: 57, 2015.

21. Cheng T, Wang L, Li Y, Huang C, Zeng L and Yang J: Differential microRNA expression in renal cell carcinoma. Oncol Lett 6: 769-776, 2013

22. Wang K, Jin W, Jin P, Fei X, Wang X and Chen X: miR-211-5p suppresses metastatic behavior by targeting SNAI1 in renal cancer. Mol Cancer Res 15: 448-456, 2017.

23. Xu J, Zhang R and Zhao J: The novel long noncoding RNA TUSC7 inhibits proliferation by sponging MiR-211 in colorectal cancer. Cell Physiol Biochem 41: 635-644, 2017.

24. Sümbül AT, Göğebakan B, Bayram S, Batmacı CY and Öztuzcu S: MicroRNA 211 expression is upregulated and associated with poor prognosis in colorectal cancer: A case-control study. Tumour Biol 36: 9703-9709, 2015.

25. Sun Y, Byon CH, Yuan K, Chen J, Mao X, Heath JM, Javed A, Zhang K, Anderson PG and Chen Y: Smooth muscle cell-specific runx2 deficiency inhibits vascular calcification. Circ Res 111: 543-552, 2012.

26. Atlasi Y, Noori R, Gaspar C, Franken P, Sacchetti A, Rafati H, Mahmoudi T, Decraene C, Calin GA, Merrill BJ and Fodde R: Wnt signaling regulates the lineage differentiation potential of mouse embryonic stem cells through Tcf3 down-regulation. PLoS Genet 9: e1003424, 2013.

27. Panizo S, Naves-Díaz M, Carrillo-López N, Martínez-Arias L, Fernández-Martín JL, Ruiz-Torres MP, Cannata-Andía JB and Rodríguez I: MicroRNAs 29b, 133b and 211 regulate vascular smooth muscle calcification mediated by high phosphorus. J Am Soc Nephrol 27: 824-834, 2016. 